\title{
La diplomacia británica y la caída de Serrano Suñer ${ }^{*}$
}

\author{
Miguel FERNÁNDEZ-LONGORIA
}

\begin{abstract}
RESUMEN
Este artículo presenta la visión británica de los acontecimientos políticos que en 1942 culminaron en la caída de Serrano Suñer. El embajador Hoare había puesto sus esperanzas en que fuese eliminado por los militares españoles con los

que estaba en contacto. Su cese tras el incidente de Begoña fue una sorpresa para los británicos, por lo que sirve de ejemplo para ilustrar

cómo el objetivo de la política exterior respecio a España. asegurar el mantenimiento de su neutralidad, fue conseguido mediante los esfuerzos de los responsables de la política exterior y por pura suerte. \author{
PALABRAS CLAVE \\ Franco, Serrano Suñer, política \\ exterior, franquismo, Segunda \\ Guerra Mundial, relaciones \\ internacionales, relaciones hispano- \\ británicas, Hoare
}

\begin{abstract}
This article presents the British perception of the political events that in 1942 resulted in Serrano Suñer's dismissal. Hoare, the ambassador in Madrid, hoped that the Spanish military, wich were in contact with the British, would remove him. His dismissal after the "Begoña incident" was a surprise, showing that the British foreign policy objetive of maintaining the Spanish neutrality was archieved by a combination of the policy maker's effort and pure luck.
\end{abstract}

\footnotetext{
* Este artículo es fruto de mi memoria investigadora, "La diplomacia británica y Franco, la percepción británica del primer franquismo (1939-1942)», presentada en la Universidad Nacional de Educación a Distancia en octubre de 2003 y realizada bajo la supervisión de Juan Avilés Farré.
} 
En el contexto de la Segunda Guerra Mundial, la España de Franco adquirió una gran importancia para los estrategas británicos durante el periodo 1939-1942. Era vital para sus intereses que los puertos españoles del Atlántico no cayesen en poder de los alemanes y que Gibraltar, "la llave del Mediterráneo", continuase disponible como base naval para la defensa de sus rutas atlánticas y mediterráneas. Por esta razón, el Foreign Office siguió con gran atención la evolución de los acontecimientos en España, dado el alineamiento diplomático e ideológico del nuevo régimen con las potencias del Eje. La política exterior británica respecto a España durante dicho periodo estuvo delimitada por la imagen que se configuraron del país y de sus gobernantes, así como de la evolución política interna, mediante la información e impresiones suministradas por su personal diplomático destacado en España.

A la hora de valorar la percepción británica de la realidad española hay que destacar que su visión de la economía y de la sociedad era bastante correcta, merced a la amplia red consular mantenida por el Reino Unido en España. Los distintos consulados elaboraban periódicamente informes sobre las condiciones de los distritos en los que se encontraban. Además, tanto los embajadores como de los agregados militares de la embajada realizaron numerosas visitas por todo el país, aunque, sus convicciones políticas les llevaba a relativizar los efectos de la represión política.

A pesar de la abundante información que tenían acerca de los acontecimientos políticos en España, dada la extensa red de contactos que mantenía la embajada con las autoridades civiles y militares, no supieron interpretar una serie de aspectos del régimen y de su evolución política. El más llamativo de los cuales es sin lugar a dudas su convencimiento de la actitud neutralista de Franco. Los diplomáticos destacados en España, como el embajador Hoare ${ }^{1}$, creían que Franco no deseaba intervenir militarmente en la Segunda Guerra Mundial y que era partidario de mantener una posición neutral ${ }^{2}$. No descartaban que Franco interviniese cuando Gran Bretaña hubiese perdido la guerra, circunstancia que para ellos era irrelevante pues significaría que su país estaba ya derrotado. Por tal motivo, como argumentaba Hoare, no se debía castigar a España mediante políticas de carácter negativo, como el bloqueo económico total, ya que sólo servirían para empujar a Franco hacia posiciones de abierta beligerancia. A pesar del rechazo hacia su régimen,

Sir Samuel Hoare (1880-195) fue secretario de estado en la India (1931-35), donde desarrolló y defendió la nueva Constitución India, siendo artífice del «India Act» (1935). Por su papel en el impopular acuerdo Hoare-Laval cuando era secretario del Foreign Office (1935), fue obligado a dimitir. Como ministro del interior (1937-39) colaboró en el desarrollo del acuerdo de Munich, lo que le marcaría como defensor de la política de apaciguamiento, dañando su carrera política. Durante la Segunda Guerra Mundial sería nombrado embajador en España (1940-44). Britannica Concise Encyclopedia. 2003. Encyclopædia Britannica Premium Service.

' Sir Samuel Hoare, Ambassador on special misson, Londres, 1946, pp. 49. 
podía ser útil a la causa aliada si mantenía a España fuera de la guerra ${ }^{3}$. Esto no quiere decir que interpretasen que Franco era favorable a los aliados. Los diplomáticos británicos sabían perfectamente que Franco no dudaba que los alemanes saldrían victoriosos del conflicto, esperando obtener ventajas del mismo sin necesidad de luchar. Por el contrario, Serrano Suñer representaba para los británicos el paradigma de la belicosidad falangista, retratándosele como un «fanático» y un «pro-nazi» que deseaba fervorosamente unirse al Eje y que detestaba las democracias occidentales ${ }^{4}$.

Por esta razón, en el periodo en el que Franco se había mostrado dispuesto a entrar en guerra, de junio a noviembre de 1940, los británicos estuvieron plenamente convencidos de que deseaba mantener la neutralidad española. Por el contrario, a pesar de las indicaciones de Hoare, los gobernantes británicos temieron la intervención española durante la primavera y el verano de 1941, especialmente tras la caída de Grecia, justo en el momento en el que Franco descartaba la entrada inmediata en el conflicto bélico ${ }^{5}$.

En el presente artículo revisaremos cuál fue la visión británica de los acontecimientos políticos en España que culminaron con la caída de Serrano Suñer y cómo su cese fue una sorpresa para los británicos. Esto nos permite ilustrar cómo el objetivo de la política británica respecto a España, asegurar el mantenimiento de su neutralidad, fue conseguido mediante los esfuerzos de los responsables de la política exterior y por pura suerte.

\section{LAS ESPERANZAS BRITÁNICAS}

La participación de los Estados Unidos en la guerra tras el ataque japonés a Pearl Harbour en diciembre de 1941 significaba que Gran Bretaña ya no luchaba sola y que tenía la seguridad de que dispondría de todos los elementos materiales y humanos necesarios para ganar la guerra. De esta manera, renacía la esperanza de la victoria en los aliados. La nueva situación bélica posibilitaba que el Foreign Office se preocupase menos por la postura espa-

\footnotetext{
${ }^{3}$ Denis Smyth, Diplomacy and strategy of survival. British policy and Franco's Spain, 1940-41, Cambridge, 1986, pp. 4-8.

${ }^{4}$ Los comentarios sobre la personalidad de Serrano Suñer y sus irritantes maneras son continuos en la correspondencia diplomática de la embajada británica. La mejor descripción nos la ofrece el ministro plenipotenciario Yencken que comentaba como el cuñado del Generalísimo se caracterizaba por tener «malas maneras que eran frecuentemente deliberadas, un rencor femenino y una mente estrecha». Además le describía como «fanático, impetuoso y de frágil salud". Annual report for 1941, FO371/31234, C514/220/41. Tanto Peterson como Hoare destacaron su postura pro-alemana, aunque algunas fuentes españolas les indicaban que Serrano Suñer realmente era pro-italiano. En cualquier caso, Hoare se quejaba en su correspondencia a Eden de lo fastidioso que era tratar con dicho personaje, ya que "era completamente ignorante de las convenciones ordinarias de la vida». FO 954/27A. También describe su figura y talante en Sir Samuel Hoare, Ambassador..., op. cit., pp. 56-57.

${ }^{5}$ Denis Smyth, Diplomacy..., op. cit., pp. 4-8.
} 
ñola. En consecuencia, la diplomacia británica empezó a protestar con mayor fuerza contra aquellas acciones españolas que eran contrarias a sus intereses, denunciando en todo momento la colaboración de algunos españoles con el $\mathrm{Eje}^{6}$. Por otro lado, gracias al alejamiento de la guerra hacia el este, los aliados pudieron ejecutar una presión material más severa para influir en la postura española. La dura presión norteamericana contribuyó a reforzar en España el deseo de permanecer al margen de la guerra mundial, consiguiendo flexibilizar la postura de Serrano Suñer hacia los aliados ${ }^{7}$.

Sin embargo, la globalización del conflicto no supuso un cambio de postura española, que se mantuvo a la expectativa, pero pensando que si se daba el momento oportuno y las condiciones adecuadas se podía intervenir en el conflicto en el lado de Alemania. La posición española se mantuvo hasta el relevo de Serrano Suñer por Jordana en septiembre de 1942, el cual inició el camino hacia la neutralidad española. A medida que se avanzaba en el año 1942, la posición española se «empantanaba en una posición de ambigüedad», al estar identificada con el Eje, cuya victoria se deseaba, pero al mismo tiempo tener que negociar con los aliados el suministro de petróleo y alimentos ${ }^{8}$.

A lo largo de 1942 España se mantuvo en una continua crisis interna, determinada por las divisiones dentro del nuevo régimen ${ }^{9}$, sin producirse modificaciones en su política exterior. Como indica Hoare en su resumen de los acontecimientos de 1941, al finalizar el año «Serrano Suñer se aferraba lúgubremente a su sillón de ministro de Asuntos Exteriores y líder de partido». Para Hoare, Franco había conseguido mantenerle en su sitio a pesar de las maniobras de los militares, contrarios a las gestiones de Serrano Suñer en materia de política exterior y al predominio de la Falange en el nuevo régi$\operatorname{men}^{10}$. Aunque a ojos del embajador británico las rivalidades internas habían adquirido una nueva dimensión en el verano de 1941 con la creación de una Junta Militar formada por los generales más influyentes del país ${ }^{11}$, éstos no habían conseguido el cese del ministro de Asuntos Exteriores, a pesar de su insistencia en que su fin estaba próximo. Por este motivo, Hoare comen-

${ }^{5}$ Leonardo CARUANA, Las relaciones bilaterales entre España y Gran Bretaña durante la Segunda Guerra Mundial, tesis doctoral, Madrid, 1989, pp. 407-418.

7 Javier Tusell, Franco, España y la ll Guerra Mundial, Madrid, 1995, pp. 286-287.

- Javier TUSELL, Franco..., op. cit., pp. 283-289.

${ }^{9}$ En cuanto a la dinámica interna, los británicos percibían que venía determinada en su mayor parte por los enfrentamientos existentes entre los nuevos gobernantes, que entorpecían la labor de reconstrucción del país. De esta manera, fueron capaces de ver como dos de las principales instituciones del país, el Ejército y la Iglesia, se oponían al predominio del partido único en la vida nacional, lo que significaba la existencia de tensiones entre los grupos dirigentes del nuevo régimen.

${ }^{10}$ Annual report for 1941 , FO371/31234, C514/220/41.

11 Aunque Aranda y otros generales usaran en sus comunicaciones con los británicos el término de "Junta de Generales», historiadores como Tusell y Payne ponen en duda su existencia. En cualquier caso, como mínimo, la pretensión de Aranda y de otros generales era la de dar la imagen de realizar contactos con los británicos en representación de todo el estamento militar. 
zaba a dudar que los militares españoles fuesen capaces de forzar la caída de Serrano Suñer.

A pesar de su desilusión porque los militares no habían conseguido eliminar a Serrano Suñer, Hoare continuó intrigando de manera muy solapada con los conspiradores españoles. Sin embargo, hay que destacar que el Foreign Office no mostró ningún apoyo a dichas intrigas, manifestando siempre una actitud de extrema prudencia. Al no haberse llevado a cabo durante 1941 ninguno de los intentos de eliminar a Serrano Suñer que habían sido anunciados por los militares españoles, el Foreign Office llegó al convencimiento de que nunca se materializarían, a pesar de que Hoare insistiera continuamente en sus comunicaciones sobre su inminencia. En opinión de Eden, la inacción de los generales justificaba su postura ${ }^{12}$.

A principios de 1942 Hoare recuperó su optimismo. En su opinión, «el viento soplaba a favor» de los intereses británicos en España, destacando las renovadas críticas de los militares a Serrano Suñer y a la Falange, así como que hubiese en Sevilla una manifestación pro-británica en la entrada del consulado ${ }^{13}$. Las fuertes críticas de los militares se venían produciendo desde una reunión del Consejo Superior del Ejército a mediados de diciembre en la que Kindelán había criticado duramente la situación política existente, no dudando en señalar que la Falange había fracasado y que Serrano Suñer era «un arribista» ${ }^{14}$.

La tensión política motivó que se disparasen en Madrid los rumores de una nueva crisis gubernamental. De esta manera, a mediados de enero la embajada británica recogió en sus comunicaciones que en Madrid se volvía a hablar del inminente cese de Serrano Suñer y la posibilidad de que se instaurase un gobierno puramente militar. El propio Hoare señalaba que algunos de los rumores eran poco fundados, aunque estaban ampliamente extendidos en los círculos políticos de Madrid que los presentaban como algo hecho. Igualmente, recogió información que indicaba que desde entonces el embajador alemán estaba presionando a Franco para que mantuviese a Serrano Suñer en su puesto, aunque Hoare no podía asegurar la veracidad de dichos rumores. En cualquier caso, Hoare pensaba que podían ser verdaderos porque a los alemanes les disgustaría perder a un ministro tan germanófilo ${ }^{15}$.

El convencimiento por parte de Hoare de la inminencia del cese de Serrano Suñer le llevó a advertir a su gobierno que en el caso de que ocurriese, la prensa americana y británica debían tratar el tema como un asunto interno español y no como una victoria aliada ${ }^{16}$. En anticipación ante tal

\footnotetext{
${ }^{12}$ Denis Smyth, Diplomacy..., op. cit., pp. 214.

${ }_{13}$ Minuta de Hoare a Eden, 5 de enero de 1942, FO 954/27B.

${ }^{14}$ Javier TUSELL, Franco..., op. cit., pp. 300.

${ }^{15}$ Minuta de Hoare a Eden, 13 de enero de 1942, FO 954/27B.

${ }^{16}$ Informe de Hoare a Eden, 11 de enero de 1942, FO 371/31234, C406/220/41.
} 
eventualidad señaló que era esencial una mayor colaboración con los americanos para sacar provecho de la situación. No obstante, criticaba que la embajada norteamericana no había adaptado sus métodos a su nueva posición de beligerancia. Hoare también se dedicó a especular sobre quién sucedería a éste al frente del ministerio de Asuntos Exteriores en el caso de que se produjese su cese. Según su acertada opinión, sería el general Jordana quien le sucediera ${ }^{17}$.

Paralelamente, Hoare pulsó la opinión de distintas personalidades españolas sobre el posible cese de Serrano Suñer. El duque de Alba, embajador español en Londres, contradijo sus argumentos manifestándole que la crisis del ministerio de Asuntos Exteriores todavía estaba en suspenso. El duque se mostró convencido ante Hoare de que pasaría mucho tiempo antes de que Serrano Suñer se fuese, debido a la inercia de Franco, aunque barajaba la posibilidad de que los generales pudiesen forzar la situación en el futuro. Hoare no se quedó satisfecho con estos argumentos y comentó que el duque parecía ignorar la lamentable situación económica de su país, que podía provocar el inmediato cese de Serrano Suñer. Además, Hoare señaló que el duque estaba complacido con las actividades de la Falange, ya que pensaba que «cuanta más cuerda les diesen más probable era que se ahorcasen " ${ }^{18}$. Los rumores sobre la marcha de Serrano Suñer continuaron y hasta el propio nuncio papal, entrevistado por Hoare en Madrid, pensaba que su salida del gobierno, como embajador a Roma, estaba próxima. Según el nuncio, en aquellos momentos Franco estaba intentando aislarlo antes de deshacerse de él ${ }^{19}$.

En aquellos momentos, Franco intentaba compensar la presión que recibía de los militares aumentando el apoyo al sector falangista. En su viaje a Barcelona en enero de 1942 hizo unas declaraciones que fueron calificadas por los diplomáticos italianos como «las más falangistas de su vida» ${ }^{20}$. Estos movimientos no pasaron desapercibidos a Hoare, que señaló que a pesar de todos los esfuerzos de los generales, Serrano Suñer seguía firme en su posición, por lo que parecía que el movimiento de los conspiradores había sufrido un profundo revés y que los cambios ministeriales se posponían. Sin embargo, como indicaba Hoare, esto no suponía un reforzamiento de la posición de Serrano Suñer. En este sentido, destacaba que quién había acompañado a Franco a Barcelona fue Arrese y no Serrano Suñer, hecho muy significativo para Hoare ${ }^{21}$.

\footnotetext{
17 Informe de Hoare a Eden, 11 de enero de 1942, FO 371/31234, C406/220/41.

${ }_{18}$ Informe de Hoare a Eden sobre su entrevista con el duque de Alba, 22 de enero de 1942, FO 371/31234, C905/220/41.

19 Informe de Hoare a Eden sobre su entrevista con el nuncio papal, 29 de enero de 1942, FO $371 / 31234, \mathrm{C} 1215 / 220 / 41$.

${ }^{20}$ Javier Tusell, Franco..., op. cit., pp. 303.

${ }^{21}$ informe de Hoare a Eden, 29 de enero de 1942, FO 371/31234, C1215/220/41.
} 
Al calmarse relativamente la situación política interna, Hoare realizó un balance de la política española, que presentaba un panorama rnuy negativo. En su opinión, España era "como un enfermo grave que necesitaba una operación pero que estaba demasiado débil para enfrentarse a los riegos derivados de la misma". Cuanto más grave era la situación interna, más necesario parecía un cambio, aunque Hoare pensaba que de momento no podía ser otra cosa que una mejora del falangismo. Dicha afirmación la realizaba a pesar de las preferencias británicas por la solución monárquica y de percibir un rechazo al falangismo por parte de la mayoría de la población y el revivir del sentimiento monárquico.

Hoare señalaba acertadamente que a pesar de todos los problemas nada ni nadie podía forzar la mano de Franco para introducir cambios en la política española. En su opinión, éste prefería practicar la peculiar política de "esperar y ver», e intentar fortalecer su posición mediante grandes escenificaciones como las concentraciones durante su visita Barcelona. Para Hoare, el claro vencedor de los acontecimientos que habían tenido lugar durante el mes anterior era Franco, que había desplazado públicamente a Serrano Suñer y evitado que los generales limitaran su poder. Hay que destacar que Hoare pensaba que los principales objetivos políticos de Franco eran mantener a España fuera de la guerra, mantenerse a toda costa en el poder y romper políticamente con su cuñado. De acuerdo a sus impresiones, la situación indicaba que Serrano Suñer estaba siendo empujado fuera del escenario político, por lo que parecía estar en el camino de su eliminación. En este sentido, seguía creyendo que los generales iban a presentar pronto un ultimátum a Franco que incluía el cese de Serrano Suñer, el cual, conocedor de su desplazamiento político había comenzado a quemar documentos en el ministerio y se dedicaba a mantener vacante la embajada de Roma, para poder tomar él dicho destino ${ }^{22}$. Respecto a la política exterior española, Hoare se congratulaba con el hecho de que España nunca había estado tan lejos de entrar en la guerra desde su llegada, por lo que se mostraba satisfecho por haber alcanzado el objetivo de su misión ${ }^{23}$.

\section{EL INCREMENTO DE LA TENSIÓN INTERNA}

A partir de ese momento, se sucedieron una serie de crisis en las que los enfrentamientos entre falangistas con militares y monárquicos eran cada

\footnotetext{
${ }^{22}$ Minuta de de Hoare a Eden, 24 de febrero de 1942, FO 371/31234, C2342/220/41.

${ }^{23}$ Churchill pensó en Hore para desarrollar una misión especial en España destinada a mejorar las relaciones con nuestro país y garantizar la neutralidad española. Su nombramiento también puede ser interpretado como una oportunidad de eliminar a este influyente personaje de la arena política británica. Dadas sus conexiones políticas y su amplia experiencia en el campo de las relaciones internacionales, tuvo no sólo un papel relevante en la formulación de los objetivos de la acción exterior respecto a España, sino también en la manera de conseguirlos.
} 
vez más ásperos. Como detectaron los británicos, los enfrentamientos trasladaron la tensión a otros ámbitos del país y terminaron degenerando en violencia física. Los observadores británicos percibían como los incidentes se multiplicaban por todo el país. Por ejemplo, recogían como los monárquicos estaban creando problemas en la Universidad de Madrid, al hacer patente su insatisfacción con el régimen o como en una manifestación de los carlistas se distribuyeron panfletos y se colocaron carteles que declaraban que los requetés «habían vertido su sangre por España, no por la presente forma de socialismo ${ }^{24}$. Uno de los principales incidentes observados fue el enfrentamiento entre Ximénez de Sandoval, jefe de gabinete de Serrano Suñer y delegado del Servicio Exterior de la Falange, con un hijo del duque de Sotomayor que resultó golpeado por pistoleros falangistas. A finales de marzo, Sandoval fue cesado, expulsado del partido y del país. Hoare destacó que se trataba de un paso más en la eliminación de Serrano Suñer, ya que era un asesor muy cercano a su persona, y había sido elegido para su puesto por encima de otros diplomáticos con mayor antigüedad ${ }^{25}$. La discordia existente daba la sensación a los observadores británicos que el país vivía en una crisis permanente, donde los rumores de dimisiones, cambios gubernamentales y conspiraciones se multiplicaban ${ }^{26}$.

A principios de abril, Hoare reconocía que la situación política había empeorado durante los meses anteriores, aunque no se había deteriorado tanto como él temía. Hoare se quejaba que los generales no habían decidido pasar a la acción y eliminar la influencia falangista, debido a que siempre querían «apostar al caballo ganador». Por otro lado, estaba convencido que, de no haber sido por la política que él había desarrollado durante los últimos años en Madrid, la situación política hubiese sido aún peor, ya que Franco y Serrano Suñer habrían empujando a España a la guerra, en lugar de haber hecho todo lo posible por mantenerse alejado de ella. Hoare también indicó que Serrano Suñer estaba flexibilizando sus posturas, mostrando que no tenía ninguna intención de romper relaciones con Gran Bretaña. Como ejemplo, señalaba que los españoles estaban entregando a los pilotos derribados de la RAF que entraban en territorio español ${ }^{27}$. Como sabemos, la flexibilidad de la postura de Serrano Suñer se debía al declive de su influencia y a la necesidad de conseguir suministros de las potencias aliadas.

Hoare seguía enterado de los planes de los generales para eliminar a Serrano Suñer, éstos pensaban que lograrían deshacerse de él antes de la llegada del siguiente invierno. En una de las múltiples entrevistas

\footnotetext{
${ }^{24}$ Informe de Hoare a Eden sobre la tensión política entre Falange y los monárquicos, 27 de marzo de 1942, FO 371/31235, C3737/220/41.

${ }^{25}$ Informe de Hoare a Eden, 29 de marzo de 1942, FO 371/31235, C3370/220/41.

${ }^{26}$ Informe de Mr. Carl Williams de la empresa Williams and Humbert Linited a Mr Makins (Foreign Office) sobre la situación en España, 2 de marzo de 1942, FO 371/31234, C2325/220/41.

${ }^{27}$ Minuta de Hoare a Eden, 2 de abril de 1942, FO 954/27B.
} 
mantenidas con el general Aranda, fue informado de que los generales no creían que se produjese ningún cambio político importante en el gobierno a corto plazo, pero que consideraban que sólo era cuestión de tiempo que Serrano Suñer fuese reemplazado. Respecto a la cuestión de la restauración de la monarquía, Hoare tuvo la impresión que los monárquicos estaban más unidos que nunca, y que demandaban que Don Juan diese muestras de iniciativa. Hoare estaba de acuerdo con su creencia de que si no se tomaban medidas en ese momento, Franco estaría en una posición tan sólida que no podría ser relevado, por lo que la posibilidad de la vuelta de la monarquía sería cada vez más lejana ${ }^{28}$.

Los incidentes entre falangistas y monárquicos continuaron, informando Hoare puntualmente de los mismos en sus comunicaciones. De este modo, mencionó, entre otros, enfrentamientos menores en Madrid, disturbios en la Universidad de Santiago que fueron severamente reprimidos, una refriega en Burgos a la salida de un grupo de carlistas de la catedral, disparos en las calles de Barcelona, disturbios en Pamplona y el cierre de la Universidad de Madrid durante tres días por enfrentamientos entre falangistas y monárquicos. Hoare resaltaba la gravedad de éste último caso, ya que los enfrentamientos resultaron en dieciocho estudiantes heridos y un carlista muerto ${ }^{29}$.

A los ojos de Hoare, Serrano Suñer estaba en aquellos momentos unicamente interesado en política internacional. La razón fundamental era que en la política interna sus acciones encontraban una feroz resistencia, al estar intentando los militares deshacerse de é $\left.\right|^{30}$. En este sentido, Hoare había interpretado la visita de Serrano Suñer a Italia a mediados del mes de junio como un intento de reforzar su posición interna. Hay que destacar que en contraste con otras visitas de Serrano Suñer a las potencias del Eje, que habían causado ansiedad a los aliados, los observadores aliados no dudaron en ningún momento que la actitud española respecto a la guerra no cambiaría tras el nuevo viaje del ministro de Asuntos Exteriores español a Italia. Para Hoare, España estaba más alejada que nunca de una posible intervención en la Segunda Guerra Mundial. La misión de Serrano Suñer a Italia no tuvo una significación destacada. Como para Mussolini el valor de la carta española en el conflicto era ya escaso, las conversaciones no tuvieron ningún resultado concreto ${ }^{31}$.

Hoare creía que la estrategia de Franco en aquellos momentos era la de intentar consolidar su posición interna atemorizando a los monárquicos, realizando movimientos de tropas (por ejemplo, trasladando efectivos militares

28 Informe de Hoare a Eden sobre una entrevista con el general Aranda, 7 de abril de 1942, FO $371 / 31235, \mathrm{C} 4001 / 220 / 41$.

29 Informe de Hoare a Eden sobre incidentes entre monárquicos, falangistas y requetés, 19 de mayo de 1942, FO 371/31235, C5193/220/41

${ }^{30}$ Informe de Hoare a Eden, 11 de julio de 1942, FO 371/31235, C6941/220/41.

${ }^{31}$ Javier Tusell, Franco..., op. cit., pp. 316-319. 
de las islas Canarias a la Península) y atrayéndose al sector moderado de Falange $^{32}$. Resulta necesario, resaltar lo acertado del juicio de Hoare, que fue capaz de captar la estrategia política de Franco. Asimismo, interpretó que la Ley de Cortes españolas, no tenía otra finalidad que reforzar su posición y asegurar su pervivencia política ${ }^{33}$. De este modo, Hoare escribió en julio que Franco estaba consolidando sus posiciones en la Falange. Hoare esperaba que este hecho se tradujese en políticas más cercanas a la línea nacional-sindicalista y que pronto fuera elaborada una nueva constitución para España. Igualmente, Hoare hizo notar que Franco estaba más opuesto que nunca a una restauración de la monarquía, a pesar de sus ambiguas declaraciones ${ }^{34}$. En cualquier caso, Hoare percibía la existencia de una distancia cada vez mayor entre el público y el régimen franquista. En su opinión, esta situación antes sólo era evidente entre los trabajadores, pero ahora los terratenientes y los hombres de negocios estaban cansados de la situación existente y defendían la restauración de la monarquía ${ }^{35}$.

Aunque Franco se negaba a cesar a Serrano Suñer, su influencia dentro del aparato del partido disminuía drásticamente. Arrese procedía a la domesticación de la Falange y, aunque no conseguía mantenerla totalmente bajo su control, sí que conseguía convertir a su organización en algo maleable en las manos de Franco. Serrano Suñer lanzó sin éxito una contraofensiva para recuperar el control de la censura de prensa exterior, que había perdido como resultado del incidente Sandoval, y publicó en la prensa unas declaraciones en las que recordaba el alineamiento español con el Eje desde la Guerra Civil con el fin de reforzar su papel político en las luchas internas en el régimen. El ambiente en Madrid se caracterizaba por las continuas intrigas políticas de uno y otro signo. Dentro del aparato estatal Carrero Blanco y Arrese eran los mayores rivales de Serrano Suñer. Arrese pretendía eliminar la influencia de Serrano Suñer en el partido, mientras que Carrero Blanco veía en su figura un obstáculo para su relación personal con Franco. La influencia de ambos personajes dentro del régimen crecía, en claro contraste con el lento desplazamiento de Serrano Suñer ${ }^{36}$.

La evolución de la política interna en España era muy relevante en aquellos momentos para los británicos, ya que se estaba preparando la Operación Torch, el desembarco aliado en el norte de África, donde la neutralidad española era clave para el éxito de la expedición. Vista la reacción de Franco a los acontecimientos internos durante los meses anteriores, Hoare llegó a la conclusión que los enfrentamientos políticos no habían hecho otra cosa que «parir un ratón». En consecuencia, no tuvo inconveniente en marcharse

\footnotetext{
${ }^{32}$ Informe de Hoare a Eden, 18 de julio de 1942, FO 371/31236, C7147/220/41.

${ }^{33}$ Informe de Hoare a Eden, 7 de julio de 1942, FO 371/31235, C6733/220/41.

${ }^{34}$ Informe de Hoare a Eden, 3 de julio de 1942, FO 371/31235, C6733/220/41.

${ }^{35}$ Informe de Hoare a Eden, 28 de julio de 1942, FO 371/31236, C7628/220/41.

${ }^{35}$ Stanley G. PAYNE, The Franco Regime, Londres, 1987, 304-306.
} 
a Londres durante unas semanas para recibir instrucciones acerca de la Operación Torch, al no esperar que se produjese ningún cambio significativo en su ausencia ${ }^{37}$.

\section{LA CAÍDA DE SERRANO SUÑER}

Los observadores británicos vieron como las rivalidades internas estallaban en un sangriento incidente en las afueras de Bilbao. Dada la ausencia ya comentada de Hoare, fue Yencken, el ministro plenipotenciario de la embajada británica, quien recogió y valoró dicho acontecimiento. En sus comunicaciones describió como en una misa en la basílica de Begoña por todos los reyes de la dinastía legítima española y por los requetés caídos en la Cruzada, unos falangistas lanzaron unas granadas a la salida del acto hiriendo a un gran número de personas ${ }^{38}$. La embajada británica recogió todos los rumores sobre el incidente, cuya reconstrucción variaba según las fuentes consultadas. Yencken concedió un mayor crédito a aquellas opiniones que señalaban a los falangistas como culpables. De esta manera, el «incidente de Begoña» fue considerado como el resultado de un plan premeditado, al demostrarse que los falangistas fueron llevados hasta el lugar de los hechos desde otras ciudades españolas y que tomaran la iniciativa en el incidente ${ }^{39}$. En cualquier caso, el incidente provocaría una de las mayores crisis de la historia del franquismo ${ }^{40}$.

Después de conocerse los hechos Franco no tomó ninguna medida inmediata, lo que dio pie a nuevos rumores sobre el incidente y sus repercusiones en la política interna ${ }^{41}$. Por otro lado, los implicados españoles atribuyeron a distintas embajadas extranjeras una intervención activa en los acontecimientos, otra indicación de hasta que punto las cuestiones de política interior se mezclaban con la política exterior ${ }^{42}$. La embajada británica no era ignorante de todos los rumores que se multiplicaban por Madrid. De este modo, Yencken recogió el rumor de que el ministro de la Guerra, el general Varela, había entregado su dimisión y que todos los ministros no falangistas del gobierno podían dimitir en breve. Sin embargo, Yencken señalaba que había versiones contradictorias sobre las posibles consecuencias de la crisis. En cualquier caso, creía que dada la gravedad de la misma, ésta no podía resolverse sin cambios ministeriales. Por otro lado, apuntaba que los generales monárquicos, con quienes estaba en continuo contacto, y a los

\footnotetext{
${ }^{37}$ Javier TUSELL, Franco..., op. cit., pp. 321.

${ }^{38}$ Informe de Yencken a Eden sobre el «incidente de Bilbao», 25 de agosto de 1942, FO 371/31236, C8368/220/41.

${ }^{39}$ Informe de Mr. Yencken a Eden, 23 de agosto de 1942, FO 371/31237, C8555/220/41.

${ }^{40}$ Stanley G. PAYNE, The Franco..., op. cit., pp. 306.

${ }^{41}$ Informe de Yencken a Eden, 28 de agosto de1942, FO $371 / 31236 \mathrm{C} 8563 / 220 / 41$

${ }^{42}$ Javier TUSELI, Franco..., op. cit., pp. 324.
} 
que veladamente apoyaba, seguían pensando que era demasiado pronto para actuar ${ }^{43}$.

La historiografía muestra la reacción de los militares ante el incidente. El general Varela, que había estado dentro del santuario de Begoña en el momento del incidente, presentó los hechos como un ataque contra el estamento militar, que incluso podía estar centrado en su persona. Inmediatamente después del incidente mandó telegramas a todos los capitanes generales sobre el asunto y protestó airadamente a Franco. El ministro de Gobernación, el general Galarza, le secundó enviando despachos a todos los gobernadores civiles. Los falangistas que habían participado en el incidente fueron juzgados por un tribunal militar. Franco se disgustó con los movimientos de sus dos ministros, al considerarlos cercanos a la insubordinación. Pero al haber conseguido Varela movilizar las simpatías de muchos de los generales de alta graduación, Franco no se atrevió a intervenir en el proceso contra los seis falangistas que habían sido arrestados, a pesar de las presiones de la Falange para que diese ese paso ${ }^{44}$.

Posteriormente, el general Varela exigió a Franco que se pidiesen mayores responsabilidades políticas a la Falange. La disputa entre ambos fue tan dura que Franco se vio obligado a prescindir de él aceptando su dimisión. El general Galarza también presentó su dimisión como ministro de Gobernación. Por otra parte, Franco cesó al vicesecretario general de la Falange, Luna, que fue acusado de estar involucrado en el incidente. De esta manera, eliminaba a un personaje cercano a Serrano Suñer, que era odiado por las demás fuerzas de la derecha española. Sin embargo, no se tomó ninguna acción contra los líderes de Falange, que mostraron un total distanciamiento con los falangistas condenados. Cuando Franco le comunicó sus decisiones a Carrero Blanco, éste le avisó que el cese de dos ministros militares sin que se produjesen ceses de sus rivales políticos podía crear nuevas complicaciones internas. Además, Carrero le instó eliminar a Serrano Suñer, ya que de lo contrario los militares y el resto de fuerzas conservadoras pensarían que la Falange había resultado vencedora y que Franco no controlaba ya la situación. Franco no dudó en dar dicho paso al estar resentido con su cuñado, que ya había perdido su confianza ${ }^{45}$. Franco se reunió con Serrano Suñer el día 3 de septiembre por la mañana para comunicarle la noticia de su cese. La actitud de espera que había mantenido durante la crisis no le salvó, ya que tanto Arrese como Carrero habían debilitado su posición. Serrano Suñer se quedó muy afectado, ya que no esperaba su cese en aquel momento. De esta manera, se consumaba la derrota política de Serrano Suñer, que había gozado de amplios poderes desde su nombra-

${ }^{43}$ Informe de Yencken a Eden sobre las consecuencias del «incidente de Bilbao», 23 de agosto de julio de 1942, FO $371 / 31236$, C8555/220/41.

${ }^{44}$ Stanley G. PAYNE, The Franco..., op. cit., pp. 308.

${ }^{45}$ Stanley G. PAYNE, The Franco..., op. cit., pp. 308-309. 
miento como ministro de Gobernación y de la plena confianza de Franco durante la mayor parte de su labor gubernativa ${ }^{46}$.

Tras el cese de Serrano Suñer, el propio 3 de septiembre se anunció la reforma del gobierno. Los observadores británicos recogieron los cambios ministeriales que eran consecuencia de la resolución de la crisis política. El general Jordana se convirtió en el nuevo ministro de Asuntos Exteriores en sustitución de Serrano Suñer, el general Asensio fue nombrado ministro de la Guerra, sustituyendo al general Varela y Blas Pérez González sustituyó al general Galarza al frente del ministerio de Gobernación. Además, se produjeron otros cambios que a los ojos de Yencken eran muy significativos. El general Franco tomaba la cabeza de la Junta Política de la Falange y Mora Figueroa sustituía a Luna como vicesecretario del partido. En su opinión, lo más destacado de estos cambios era que dejaban a Serrano Suñer completamente fuera de la vida política española. Los informadores de los británicos reforzaban dicha impresión asegurando que no se le iba a dar ningún otro cargo público en Espa$n a^{47}$. Según Hoare, Franco había ofrecido el puesto de ministro de Gobernación al general Aranda, que no lo aceptó al no saber cual era la futura política de Franco ${ }^{48}$.

Del general Jordana, el sustituto de Serrano Suñer, el Foreign Office resaltaba que era una persona muy cercana a Franco y que tenía gran habilidad e inteligencia en el manejo de los asuntos exteriores. Además, se le consideraba monárquico, y se aseguraba que no tenía conexiones con la Falange. Del general Asensio se comentaba que era considerado como uno de los mejores soldados de España, destacando el rumor que apuntaba a que el propio Varela le había recomendado como su sucesor. Por esta razón, los británicos asumieron que su visión de la política interna y exterior era coincidente: ambos apoyaban la restauración monárquica, tenían un profundo respeto por el ejército alemán y estaban determinados en mantener a España fuera de la guerra. Además, creían que el nuevo ministro de Gobernación sería capaz de mantener el equilibrio entre las distintas facciones políticas enfrentadas. Por otro lado, consideraban que aunque los cambios eran fruto de rivalidades internas, tendrían efecto en la política exterior española ${ }^{49}$. Esto prueba que hasta los propios británicos eran conscientes de cómo se mezclaban las cuestiones internas y la política exterior en la España de la inmediata posguerra. Finalmente, conviene destacar que a pesar del cese de Serrano Suñer, el Foreign Office percibía como la posición del

\footnotetext{
${ }^{46}$ Javier TuselL, Franco..., op. cit., pp. 326.

${ }_{47}$ Informe de Yencken a Eden sobre los cambios ministeriales en España, 3 de septiembre de 1942, FO $371 / 31236, \mathrm{C} 8568 / 220 / 41$

48 Informe de Hoare a Eden, 27 de octubre de 1942, FO 371/31238, C10439/220/41.

${ }^{49}$ Minuta de Mr. Williams (Foreign Office), 4 de septiembre de 1942, FO $371 / 31237$, C8604/220/41.
} 
ejército, falangistas y tradicionalistas en el gobierno mantenía más o menos el mismo equilibrio que antes ${ }^{50}$. En efecto, como bien apreciaron los británicos, la reorganización del gobierno emprendida por Franco fue un ejercicio más de su calculada táctica de equilibrar a las distintas tendencias de su régimen, por lo que no apartó del poder a ninguna de ellas. Como señalaba Hoare, era "una solución típica de Franco», al eliminar simultáneamente a Serrano Suñer y Varela ${ }^{51}$.

Ninguna de las tendencias rivales del régimen -los militares, falangistas, carlistas o monárquicos - se mostró plenamente satisfecha con el resultado de la crisis. A pesar de ello, la combinación de septiembre de 1942, estaba perfectamente diseñada para mantener dicho equilibrio enfrentando a unas contra otras, resultando en uno de los gobiernos más estables desde el final de la Guerra Civil. La relevancia política de la crisis vino dada por la eliminación de Serrano Suñer, personaje que desde febrero de 1937 había desempeñado un papel vital en el impulso del Nuevo Estado y en cual Franco había confiado tareas claves tanto en materias domésticas como en política exterior. Por su parte, Franco demostró una gran habilidad para superar dos graves crisis políticas en el seno de su régimen mediante el manejo de las distintas tendencias que lo componían. La combinación política resultante de la crisis reforzaba a Franco, que dominaría completamente el panorama político español ${ }^{52}$, apoyándose en los sectores moderados de la Falange como contrapeso de las aspiraciones monárquicas. Sin embargo, de cara a los británicos, los generales presentaron el resultado de la crisis como una victoria política propia, presumiendo ante Hoare que podían deshacerse del régimen falangista cuando ellos quisieran, siempre que los alemanes no interviniesen ${ }^{53}$.

La crisis política de 1942 fue un acontecimiento de primer orden en la trayectoria del régimen franquista, apreciado como tal por la diplomacia británica, ya que suponía el final de la «tentación fascista e imperial», utilizando la terminología de Tusell. Los cambios políticos provocados por la crisis motivaron en el plano de la política interna la culminación de la domesticación de la Falange y la amenaza de la restauración monárquica a la posición política de Franco. En el plano exterior, significaba un giro paulatino pero decidido hacia la neutralidad, impulsado por el general Jordana.

El primer signo de cambio en el régimen impulsó la creencia que era posible avanzar hacia una inmediata restauración, ya que desaparecía el hombre fuerte del régimen que era considerado como el principal obstáculo para llevarla a cabo. Lógicamente, el reemplazo de Franco más lógico y aceptable

\footnotetext{
${ }^{50}$ Informe de Mr. Bowker a Mr. Roberts, 22 de septiembre de 1942, FO 371/31237, C9320/220/41.

5. Sir Samuel Hoare, Ambassador..., op. cit., pp. 166.

52 Stanley G. Payne, The Franco..., op. cit., pp. 311-312.

${ }^{53}$ Informe de Hoare a Eden, 7 de octubre de 1942, FO 371/31228, C9979/80/41.
} 
para los aliados era Don Juan. Hasta ese momento Don Juan había mantenido una posición ambigua, incluso se podría decir que favorable al Eje durante los primeros años de la guerra ${ }^{54}$. Aunque su postura no cambió públicamente hasta los desembarcos aliados en el norte de África, al conocerse los resultados de la crisis de 1942 sus principales asesores comenzaron a estudiar la posibilidad de lograr una inmediata restauración monárquica, incluso contactando a los británicos para buscar su apoyo.

Sin embargo, aunque éstos veían con agrado la posibilidad de la restauración, no apoyaron abiertamente a dicho movimiento. De este modo, los británicos aseguraron a los monárquicos, representados por el general Kindelán, que la posición oficial británica sobre la posibilidad de la restauración de la monarquía en España era que se trataba de un asunto puramente interno, debiendo ser los españoles quienes decidiesen sobre la forma más conveniente de gobierno para su país y cuándo fuese oportuno implantarla ${ }^{55}$. Yencken aparte de informar a los monárquicos de la postura del gobierno británico de no involucrarse en la política española, intentó con su declaración evitar que los falangistas desacreditasen a los monárquicos acusándoles de estar en la paga de los británicos, como sucedía en aquellos momentos con algunos generales españoles. Sobre la cuestión de la restauración, la embajada británica consideraba que el regreso inmediato de la monarquía era poco práctico. De acuerdo a su percepción, los principales generales y líderes monárquicos en España habían decidido que como un preludio a la restauración era esencial la formación de un gobierno militar y que Don Juan definiese públicamente cual sería su política ${ }^{56}$.

Aunque Franco no quisiera realizar ningún cambio en la política exterior, el general Jordana tenía una postura personal más tendente a la neutralidad y garantizaba de cara al Ejército que un puesto tan clave como el suyo no estaba en manos de una persona no calificada para ello ${ }^{57}$. Jordana condujo a la política exterior española hacia la estricta neutralidad, que se afianzó después del desembarco de los aliados en el norte de África. Tras su nombramiento, Hoare le describió como una persona favorable a la neutralidad española, cuya prudencia evitó un cambio brusco en materia de política exterior. Después de varias semanas de trato, le valoraba como una persona honesta y sincera ${ }^{58}$, juzgando que su llegada había sido muy favorable para los intereses británicos. De este modo, señalaba que desde que se hizo cargo de

\footnotetext{
${ }^{54}$ No olvidemos que Roma fue la residencia de su padre Alfonso XIII hasta su muerte y que algunos intermediarios de Don Juan habían sondeado a los alemanes acerca de la posibilidad de una restauración de la monarquía en España dentro del nuevo orden europeo que establecería el Tercer Reich.

${ }^{55}$ Informe de Mr. Borker a Mr. Roberts (Foreign Office), 13 de octubre de 1942, FO $371 / 31228$, C10067/80/41.

${ }^{56}$ Informe de Yencken a Eden, 1 de octubre de 1942, FO 371/31238, C9716/220/41.

${ }^{57}$ Javier TUSELL, Franco..., op. cit., pp. 331-337.

${ }^{53}$ Javier TuSELL, Franco..., op. cit., pp. 348.
} 
su puesto, en tan sólo unas semanas se había notado una notable mejoría en las relaciones bilaterales, como en el caso de los prisioneros de guerra ${ }^{59}$.

Los británicos, aunque veían la posibilidad de intervención española en el conflicto como algo lejano, celebraron el cambio de orientación de la política exterior española que suponía el nombramiento del general Jordana. La caída de Serrano Suñer fue un golpe de suerte para los británicos, como el propio Hoare reconoció al afirmar que «la providencia» les ayudó en el cese de Serrano Suñer justo antes del lanzamiento de la Operación Torch ${ }^{60}$.

A lo largo del artículo también hemos visto como los diplomáticos británicos daban una excesiva relevancia a la influencia política de sus contactos entre los militares, como el general Aranda. Este último fue un buen informador, pero en ningún caso tenía relevancia política alguna, no pasando de ser un intrigante cuyas actividades eran bien conocidas por Franco y Serrano Suñer, que le denunció al embajador alemán ${ }^{61}$. Aunque Hoare estuvo relacionado con un grupo muy numeroso de generales, sus contactos no representaban a la totalidad del estamento militar. Los generales a los que Hoare trataba, como Aranda, Kindelán u Orgaz, todavía perecían considerar al Generalísimo como un "primus inter pares", pero, su influencia política estaba en declive, al apoyarse Franco en oficiales y generales más jóvenes, como Carrero Blanco, para los que era el Caudillo por encima de todo ${ }^{62}$. Además, la dictadura de Franco no era de carácter militar, en la que dicho colectivo rigiese los destinos de la nación, se trataba de una dictadura personal.

${ }^{59}$ Informe de Hoare a Eden, 20 de octubre de 1942, FO 371/31238, C10304/220/44.

${ }^{60}$ Sir Samuel HoAre, Ambassador..., op. cit., pp. 164.

s) Denis SмYTH, Diplomacy..., op. cit., pp. 211.

62 Javier TUSELL, La dictadura..., op. cit., pp. 178-181. 